\title{
Risk of perforation in balloon dilation associated with steroid injection for preventing esophageal stricture after endoscopic submucosal dissection
}

\section{(๑) $\odot \ominus$}

\author{
Authors \\ Yoshiki Tsujii ${ }^{1}$, Yoshito Hayashi ${ }^{1}$, Naoki Kawai ${ }^{2}$, Takuya Yamada ${ }^{3}$, Katsumi Yamamoto ${ }^{4,5}$, Shiro Hayashi ${ }^{4}$, Shunsuke \\ Yoshii ${ }^{1}$, Kengo Nagai ${ }^{1}$, Takuya Inoue ${ }^{2}$, Tsutomu Nishida ${ }^{4}$, Hideki lijima ${ }^{1}$, Eiji Mita ${ }^{3}$, Atsuo Inoue ${ }^{2}$, Tetsuo Takehara ${ }^{1}$
}

Institutions

1 Department of Gastroenterology and Hepatology, Osaka University Graduate School of Medicine, Suita, Osaka, Japan

2 Department of Gastroenterology, Osaka General Medical Center, Osaka, Japan

3 Department of Gastroenterology, Osaka National Hospital, National Hospital Organization, Osaka, Japan

4 Department of Gastroenterology, Toyonaka Municipal Hospital, Toyonaka, Japan

5 Department of Gastroenterology, Osaka Hospital, Japan Community Health Care Organization, Osaka, Japan

submitted 16.12 .2016

accepted after revision 15.3.2017

Bibliography

DOI https://doi.org/10.1055/s-0043-110077 |

Endoscopy International Open 2017; 05: E573-E579

(c) Georg Thieme Verlag KG Stuttgart · New York

ISSN 2364-3722

Corresponding author

Tetsuo Takehara, MD PhD, Department of Gastroenterology and Hepatology, Osaka University Graduate School of Medicine, 2-2 Yamadaoka, Suita, Osaka 565-0871, Japan Fax: +81-6-6879-3629

takehara@gh.med.osaka-u.ac.jp

\section{ABSTRACT}

Background and study aims Endoscopic local steroid injection (LSI) has been used to prevent esophageal strictures after endoscopic submucosal dissection (ESD) for superficial esophageal neoplasms (SENs). This study aimed to evaluate the safety and efficacy of LSI therapy.

Patients and methods From May 2007 to September 2014, at four institutions, 40 consecutive patients with SENs were treated with ESD that left a mucosal defect of more than three-quarters of the esophageal circumference. Two patients who underwent esophagectomy after ESD were excluded, and 38 patients were analyzed. The incidence of post-ESD strictures and adverse events associated with LSI were retrospectively investigated.

Results Prophylactic LSI was administered in 28 patients (LSI group), and not administered in 10 patients (Non-prevention group). Post-ESD stricture rates were significantly lower in the LSI group (43\%) than in the Non-prevention group (90\%) $(P=0.012)$. Endoscopic balloon dilation (EBD) was conducted in 11 patients (39\%) in the LSI group and in $7(70 \%)$ in the Non-prevention group. In the LSI group, perforation caused by EBD occurred in five patients, while in the Non-prevention group, it occurred in only one patient who had received subsequent LSI before the perforation. Four patients with perforation successfully recovered after conservative therapy, but the other two patients required surgical treatment. A review of follow-up examinations with endoscopic ultrasonography and narrow-band imaging showed impaired ulcer-healing process after LSI.

Conclusion LSI is useful for preventing post-ESD strictures, but it appears to increase the risk of perforation in cases of EBD.

\section{Introduction}

Endoscopic submucosal dissection (ESD) for superficial esophageal neoplasms (SENs) is currently a widespread procedure. Although favorable clinical outcomes have been reported [1-3], stricture formation after endoscopic resection of large SENs re- mains a major problem [4]. A lesion with more than half of the luminal circumference is independently associated with postESD stricture [1], and the frequency of stricture formation after ESD, with a resected area greater than three-quarters of the luminal circumference, is reportedly $70-90 \%$ [5-7]. 
Recently, prophylactic endoscopic local steroid injection (LSI) has been used to prevent initial post-ESD strictures $[4,8$, 9], and subsequent LSI has also been adopted for recurrent stenosis in combination with endoscopic balloon dilation (EBD) $[10,11]$. Some studies have reported the benefits of steroid administration $[8,9,12]$. However, the safety and efficacy of LSI therapy have yet to be fully evaluated. This multicenter study aimed to investigate retrospectively the outcomes after esophageal ESD with a wide circumferential mucosal defect and to identify the incidence of strictures and complications associated with LSI.

\section{Patients and methods}

\section{Patients}

From May 2007 to September 2014, in one university hospital and three tertiary care centers, 40 consecutive patients with SENs were treated by ESD that left a mucosal defect involving more than three-quarters of the luminal circumference. Of these, two patients who underwent esophagectomy after ESD were excluded, and 38 patients were analyzed. This study was approved by the Institutional Review Boards of all participating institutions.

\section{ESD procedure}

This was performed as previously described [13]. One or two electrosurgical knives, such as a flush knife (DK-2618JN, DK2618JB; Fujifilm, Tokyo, Japan) or a stag beetle (SB) knife (MD47704, MD-47703; Sumitomo Bakelite, Tokyo, Japan) were used with an ICC200 or VIO 300 D (Erbe, Tübingen, Germany) electrosurgical generator. Saline solution, $10 \%$ glycerin solution, or $0.4 \%$ sodium hyaluronic acid solution (MucoUp; Johnson \& Johnson K.K., Tokyo, Japan) was injected into the submucosa. Major bleeding was stopped using hemostatic forceps (HDB2422/HDB2418; Pentax Hoya Co, Tokyo, Japan) or a coagrasper (FD-410LR; Olympus, Tokyo, Japan) using the coagulation mode.

\section{Steroid therapy}

Since November 2009, LSI has been administered mainly for lesions larger than half the luminal circumference according to the judgment of operators in each institution. With regard to the method, dexamethasone sodium phosphate was used multiple times as necessary, and the use of triamcinolone acetonide (Kenacort; Bristol-Myers Squibb Co., Tokyo, Japan) once just after ESD as proposed by Hanaoka et al. has been introduced since 2012 [8]. Dexamethasone sodium phosphate or triamcinolone acetonide was diluted with saline to make a $1 \mathrm{mg} / \mathrm{mL}$ or $4-8 \mathrm{mg} / \mathrm{mL}$ solution, respectively. The steroid solution of $0.5-1.0 \mathrm{~mL}$ was injected $8-20$ times evenly into the submucosal tissue of the ulcer bed. Prophylactic LSI was defined as that administered to prevent initial stricture formation after ESD. Some patients who had recurrent strictures received subsequent LSI concomitant with EBD. Subsequent LSI was defined as that administered just after EBD for ESD-related esophageal strictures. In every case, the steroid solution was carefully injected into the submucosal layer to avoid possible muscle damage.

\section{Follow-up endoscopy}

Follow-up endoscopy after ESD was performed on demand whenever patients complained of dysphagia. In patients without dysphagia, endoscopy was usually performed a few months after ESD to confirm ulcer healing, to evaluate any possible stricture, and to rule out residual disease.

\section{Stricture and EBD}

A stricture was defined as a situation where the passage of a standard endoscope was obstructed. EBD was conducted using a CRE balloon dilator (Boston Scientific Co, Tokyo, Japan) against the stricture and repeatedly performed in several sessions until the passage of a standard scope was obtained. The size of dilators varied from $12 \mathrm{~mm}$ to $20 \mathrm{~mm}$ according to the degree of the stricture. When the patient complained of persistent dysphagia in spite of the passage of a standard scope, we performed EBD once, but EBD was mostly discontinued after that irrespective of symptomatic improvement.

\section{Efficacy and safety of LSI}

To evaluate the efficacy of LSI, the frequency of post-ESD strictures was retrospectively investigated and compared by the presence or absence of prophylactic LSI. For the safety assessment of LSI, the incidence of adverse events in EBD, such as perforations or bleeding, was also compared between the two groups. Perforation was diagnosed if mediastinal connective tissue was observed during EBD and mediastinal emphysema was confirmed on computed tomography. Bleeding was considered to be apparent hematemesis that required hemostatic therapy.

\section{Statistical analysis}

All continuous variables were expressed as the median value and range. Categorical variables were expressed as the number or frequency of each category. Differences in dichotomous variables were examined using the $x^{2}$ test or Fisher's exact test, where appropriate. Differences in continuous variables between groups were examined using the Wilcoxon test. All statistical analyses were performed using JMP software (ver. 10.0.2, SAS Institute, Inc., Cary, NC, United States). A P value $<0.05$ was considered to be statistically significant.

\section{Results}

\section{Characteristics}

Clinical findings for the patients and lesions are shown in $>\mathrm{Ta}$ ble 1. Prophylactic LSI was administered in 28 patients (men, 27; median age, 69 [range 51-83] years) (LSI group), and not administered in 10 patients (men, 10; median age, 73 [range $66-80$ ] years) (Non-prevention group). The proportion of lesions with more than two-thirds of the luminal circumference was higher in the LSI group (10/28; 36\%) than in the Non-prevention group $(2 / 10 ; 20 \%)$, but there were no significant differences between the two groups in the background factors, in- 
- Table 1 Clinical findings for the patients and lesions.

\begin{tabular}{|c|c|c|c|}
\hline & \multicolumn{2}{|c|}{ Prophylactic steroid injection } & \multirow[b]{2}{*}{$P$ value } \\
\hline & $\begin{array}{l}\text { Present (LSI group) } \\
\mathrm{n}=\mathbf{2 8}\end{array}$ & $\begin{array}{l}\text { Absent (Non-prevention group) } \\
n=10\end{array}$ & \\
\hline Gender, male/female & $27: 1$ & 10:0 & n.s. \\
\hline Age, median [range], years & $69[51-83]$ & $73[66-80]$ & n.s. \\
\hline Tumor size, median [range], mm & $40[18-85]$ & $37[30-50]$ & n.s. \\
\hline Location, upper/middle/lower esophagus & $3: 16: 9$ & $3: 6: 1$ & n.s. \\
\hline Luminal circumference of tumor, $<2 / 3: \geq 2 / 3$ & $18: 10$ & $8: 2$ & n.s. \\
\hline Depth of invasion, EP-LPM/MM-SM1/SM2 & $17: 6: 4$ & $6: 2: 2$ & n.s. \\
\hline Adjuvant chemoradiotherapy, n & 4 & 1 & n.s. \\
\hline
\end{tabular}

- Table 2 Association of prophylactic local steroid injection (LSI) with post-ESD stricture, endoscopic balloon dilation (EBD), and perforation in EBD.

\begin{tabular}{|c|c|c|c|}
\hline & \multicolumn{2}{|c|}{ Prophylactic steroid injection } & \multirow[b]{2}{*}{$P$ value } \\
\hline & $\begin{array}{l}\text { Present (LSI group) } \\
\mathrm{n}=\mathbf{2 8}\end{array}$ & $\begin{array}{l}\text { Absent (Non-prevention group) } \\
n=10\end{array}$ & \\
\hline Post-ESD stricture, n (\%) & $12(43)$ & $9(90)$ & 0.012 \\
\hline Period from ESD to stricture, median [range], days & $32[7-43]$ & $19[12-22]$ & n.s. \\
\hline Number of EBD patients, $\mathrm{n}(\%)$ & $11(39)$ & $7(70)$ & n.s. \\
\hline Total number of EBD procedures per case, median [range] & $8[1-186]$ & $5[2-12]$ & n.s. \\
\hline Max. diameter during EBD, median [range], mm & $18[12-20]$ & $18[12-20]$ & n.s. \\
\hline Perforation in EBD, $\mathrm{n}$ & 5 & 1 & n.s. \\
\hline
\end{tabular}

cluding the size, location, invasion depth of the lesion, or the presence or absence of adjuvant chemoradiotherapy.

\section{Post-ESD stricture and EBD}

Post-ESD stricture rates were significantly lower in the LSI group (43\%) than in the Non-prevention group (90\%) $(P=$ 0.012), as shown in - Table 2. Median periods from ESD to stricture formation were 32 days in the LSI group and 19 days in the Non-prevention group. EBD was performed in 11 patients (39\%) in the LSI group and 7 (70\%) in the Non-prevention group. The number of EBD cases and EBD sessions per case were not significantly different between the two groups.

\section{Perforation in EBD}

In the LSI group, perforation caused by EBD occurred in five patients (45\%), while in the Non-prevention group, it occurred in only one patient (14\%) who had received subsequent LSI before the incident ( $\triangleright$ Fig. 1 ). Therefore, perforation related to EBD occurred in only six patients who had received prophylactic or subsequent LSI previously. The maximum diameter during EBD was not significantly different between the perforation cases $(n=6$, median 17.25 [range 15-18] mm) and the other patients ( $n=32$, median 18 [range $12-20$ ] mm).

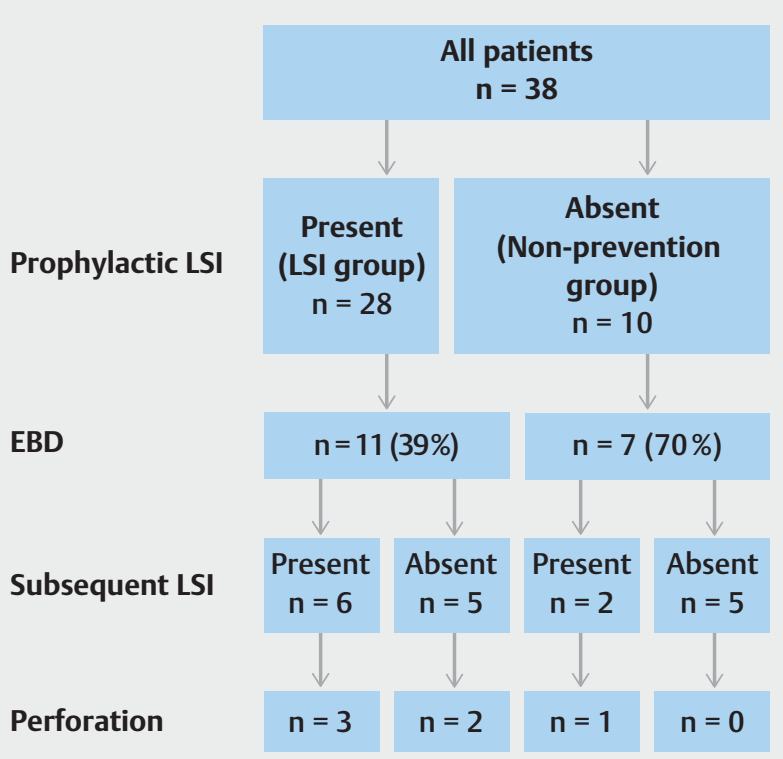

- Fig. 1 Flow diagram of outcomes by the presence or absence of prophylactic local steroid injection (LSI) and subsequent LSI. 
- Table 3 Clinical features and outcomes of six patients with perforations during endoscopic balloon dilation (EBD).

\begin{tabular}{|c|c|c|c|c|c|c|c|c|c|c|c|c|c|}
\hline $\begin{array}{l}\text { Pa- } \\
\text { tient } \\
\text { no. }\end{array}$ & $\begin{array}{l}\text { Age } \\
\text { and } \\
\text { sex }\end{array}$ & $\begin{array}{l}\text { Tumor } \\
\text { size, } \\
\mathrm{mm}\end{array}$ & $\begin{array}{l}\text { Tumor } \\
\text { loca- } \\
\text { tion }\end{array}$ & $\begin{array}{l}\text { Luminal } \\
\text { circum- } \\
\text { ference } \\
\text { of tumor }\end{array}$ & $\begin{array}{l}\text { Depth } \\
\text { of tu- } \\
\text { mor }\end{array}$ & $\begin{array}{l}\text { Adjuvant } \\
\text { chemora- } \\
\text { diation }\end{array}$ & $\begin{array}{l}\text { Prophy- } \\
\text { lactic } \\
\text { steroid } \\
\text { injection }\end{array}$ & $\begin{array}{l}\text { Type } \\
\text { of } \\
\text { ster- } \\
\text { oid }\end{array}$ & $\begin{array}{l}\text { Amount } \\
\text { of total } \\
\text { steroid } \\
\text { adminis- } \\
\text { tration, } \\
\text { mg }\end{array}$ & $\begin{array}{l}\text { Total } \\
\text { number } \\
\text { of EBD } \\
\text { sessions }\end{array}$ & $\begin{array}{l}\text { Max. di- } \\
\text { ameter } \\
\text { during } \\
\text { EBD, mm }\end{array}$ & $\begin{array}{l}\text { Clinical } \\
\text { course } \\
\text { after per- } \\
\text { foration }\end{array}$ & $\begin{array}{l}\text { Hospital } \\
\text { stay after } \\
\text { perfora- } \\
\text { tion, days }\end{array}$ \\
\hline \#1 & $70 M$ & 50 & U & $\geq 2 / 3$ & LPM & Absent & Absent & TA & 80 & 4 & 18 & $\begin{array}{l}\text { Required } \\
\text { surgery }\end{array}$ & 43 \\
\hline \#2 & $61 \mathrm{M}$ & 40 & $U$ & $<2 / 3$ & MM & Absent & Present & TA & 80 & 1 & 18 & $\begin{array}{l}\text { Cured by } \\
\text { conserva- } \\
\text { tive man- } \\
\text { agement }\end{array}$ & 62 \\
\hline \#3 & $75 \mathrm{~F}$ & 40 & U & $\geq 2 / 3$ & EP & Absent & Present & TA & 80 & 1 & 15 & $\begin{array}{l}\text { Cured by } \\
\text { conserva- } \\
\text { tive man- } \\
\text { agement }\end{array}$ & 77 \\
\hline \#4 & $69 M$ & 37 & $M$ & $\geq 2 / 3$ & MM & Absent & Present & DEX & 20 & 20 & 15 & $\begin{array}{l}\text { Cured by } \\
\text { conserva- } \\
\text { tive man- } \\
\text { agement }\end{array}$ & 55 \\
\hline \#5 & $74 \mathrm{M}$ & 58 & L & $\geq 2 / 3$ & LPM & Absent & Present & TA & 480 & 2 & 18 & $\begin{array}{l}\text { Required } \\
\text { surgery }\end{array}$ & 218 \\
\hline \#6 & $68 \mathrm{M}$ & 52 & U & $\geq 2 / 3$ & $\begin{array}{l}\text { SM } \\
700 \mu \mathrm{m}\end{array}$ & Absent & Present & TA & 785 & 186 & 16.5 & $\begin{array}{l}\text { Cured by } \\
\text { conserva- } \\
\text { tive man- } \\
\text { agement }\end{array}$ & 107 \\
\hline
\end{tabular}

The clinicopathological features and clinical outcomes of the six perforation cases are shown in $>$ Table 3. All institutions experienced perforations and all incidents occurred when the maximum diameter in EBD was greater than or equal to 15 $\mathrm{mm}$. Four patients with perforations (\#2, \#3, \#4, and \#6) successfully recovered after conservative therapy by total parenteral nutrition without eating or drinking, antibiotic administration, and transnasal insertion of a decompression tube into the perforated site, but the other two patients (\#1 and \#5) required surgical treatment ( $\triangleright$ Fig. $2 a-f)$. Patient \#2 was effectively cured by endoscopic closure using polyglycolic acid sheets [14]. Patient \#6 refused surgery despite our strong recommendation because the cancerous lesion had invaded into the submucosa and was beyond the curative criteria. He required a massive amount of steroid injections and frequent EBD sessions for the refractory stricture. Neither bleeding nor mortality related to EBD sessions occurred in any patient.

\section{Endoscopic findings in the follow-up examination}

For additional exploration, we reviewed the endoscopic findings during the follow-up examinations for patients with or without LSI (endoscopic ultrasonography [EUS] for three patients in each group), and found some distinct differences between them. On the surface of the healing-staged ulcer after
LSI, randomly-arranged microvessels like a collapsed whorl were observed with narrow-band imaging in more than $10 \mathrm{pa}$ tients ( $\triangleright$ Fig. 3a, b). On EUS, the border between the submucosa and muscle layer remained obscure even a few months after ESD. A partial rupture in the muscle layer was suspected in two of three patients ( $\triangleright$ Fig. $\mathbf{3 c}$ ).

In those patients without LSI, the artificial ulcer was fully covered with the epithelium within 1 or 2 months after ESD ( $\triangleright$ Fig.3d). Microvessels on the surface concentrated to the center of the ulcer in an orderly fashion. Normal layer structure was recognized soon after ESD in all three patients ( $\mathbf{F i g . 3 e , f ) . ~}$

\section{Discussion}

Perforation during EBD has been reported to occur in $0.4-1.1 \%$ of procedures and $4.1-9.2 \%$ of patients treated for esophageal stricture after endoscopic resection $[15,16]$. However, evidence about the risk of EBD after LSI is still lacking. In this study, we retrospectively investigated the outcomes after esophageal ESD for large lesions and studied the incidence of strictures and complications associated with LSI.

This study demonstrated the preventive effects of LSI on stricture formation after esophageal ESD. Our analysis of patients whose post-ESD mucosal defect covered more than 

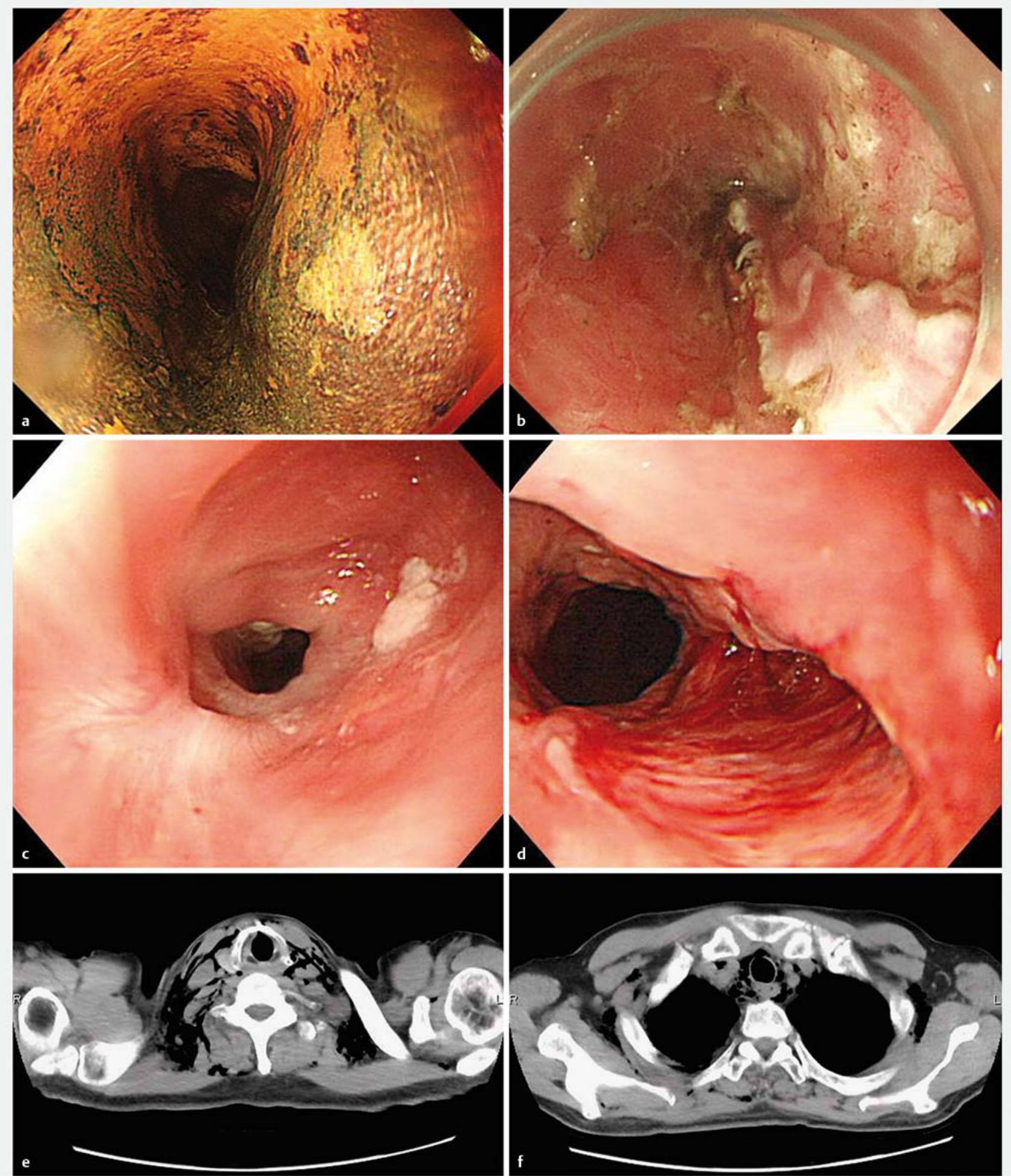

- Fig. 2 Perforation during endoscopic balloon dilation (EBD): patient \#1. a Endoscopic submucosal dissection (ESD) was performed for the lesion located in the upper esophagus that was $50 \mathrm{~mm}$ in size and occupied more than two-thirds of the luminal circumference. $\mathbf{b}$ The mucosal defect just after ESD affects more than three-quarters of the circumference of the lumen. c Forty-five days after ESD, an esophageal stricture developed and the first EBD was conducted. Fifteen days later, a second EBD was performed for re-stenosis and 40 mg of triamcinolone acetonide was injected into the lacerated wound. $\mathbf{d}$ A third EBD performed for re-stenosis after an additional 15 days resulted in perforation followed by mediastinitis. e, $\mathbf{f}$ Pneumomediastinum with massive subcutaneous emphysema was observed in different computed tomography (CT) slices. Three days after ineffective conservative treatment, the patient underwent surgery (drainage of the mediastinal cavity, covering by sternocleidomastoid muscle, and suture of the cervical esophagus). 


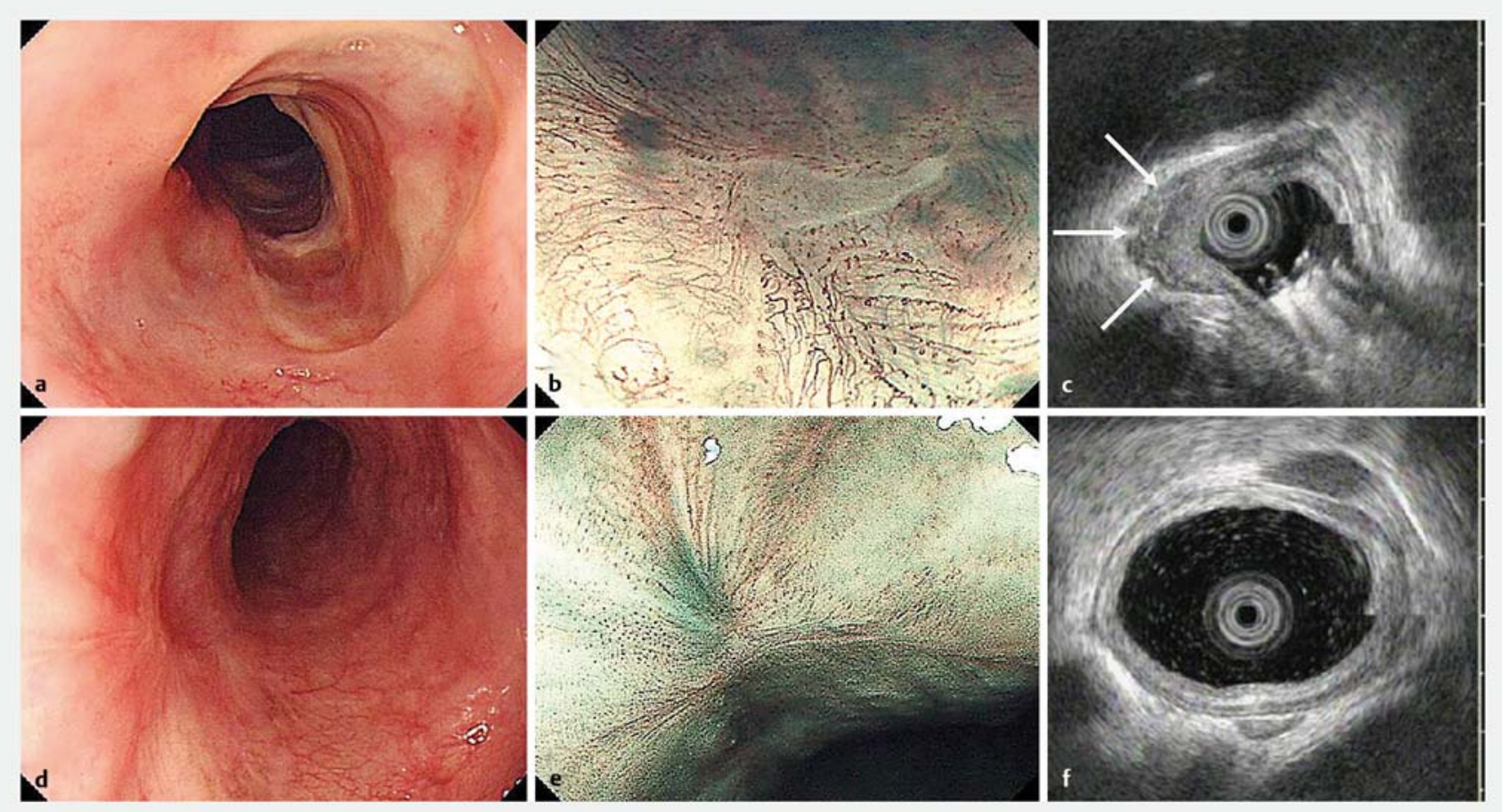

- Fig. 3 Endoscopic view after steroid injection $(\mathbf{a}-\mathbf{c})$ versus no injection $(\mathbf{d}-\mathbf{f})$. a Even 8 weeks after endoscopic submucosal dissection (ESD), the artificial ulcer has not been fully covered with epithelium, and a white coat remains on the ulcer. $\mathbf{b}$ On the surface of the ulcer, randomly arranged microvessels like a collapsed whorl are observed by magnifying endoscopy with narrow-band imaging. c On endoscopic ultrasonography (EUS), the border between the submucosa and muscle layer is obscure, and a partial rupture in the muscle layer was suspected (arrows). d In the case without steroid injection, the artificial ulcer is fully covered with regenerating epithelium 6 weeks after ESD. e Microvessels on the surface concentrate to the center of the ulcer. $\mathbf{f}$ Normal layer structure is observed on EUS and the scar change is difficult to observe.

three-quarters of the circumference revealed a significant difference in the stricture rates between the LSI group (43\%) and the Non-prevention group (90\%), which was consistent with a previous report [6].

Of note, perforation during EBD only occurred in patients who had received LSI. All six perforation cases necessitated prolonged hospitalization and two patients required surgical treatment. Honda et al. previously described that LSI led not only to delayed epithelialization and extended inflammation in the artificial ulcer but also to fibrotic changes and transmural destruction of the muscularis propria, using a canine model [17]. Furthermore, Nonaka et al. recently showed histopathological differences such as those in the shape and arrangement of $\alpha$ smooth muscle actin (SMA)-positive cells between pig models that received and did not receive LSI during the healing process of esophageal mucosal defects [18].

In the follow-up examinations in our study, very different images of the wound surface and layer structure were observed endoscopically between patients who received LSI and those who did not. Our findings have important implications because they may reflect the disordered repair of the post-ESD ulcer as a result of LSI. The fact that all institutions experienced perforations only in patients with prior $L S I$ is unlikely to be coincidental. Therefore, we speculate that LSI reduces the strength and elasticity of the esophageal wall, resulting in vulnerability to dilating pressure.
Currently, we carefully perform EBD in patients with a history of LSI only when the scope cannot be passed through and the patient experiences persistent dysphagia. In the treatment for such patients, the maximum diameter of the dilated balloon should probably be limited to $12 \mathrm{~mm}$ at the first session and increased in a stepwise manner over several sessions, because all perforations in our cohort occurred when the maximum balloon diameter was more than or equal to $15 \mathrm{~mm}$. The rate of perforation in the Non-prevention group in our study was consistent with other previous data. Thus, after LSI, it seems to be hazardous to perform EBD in the conventional way.

Yamashina et al. presented a case of delayed perforation related to tissue damage caused by LSI and noted that direct puncture of the muscularis propria by an injection needle should be avoided during the procedure [11]. Although we have experienced no delayed perforation, a partial rupture in the muscle layer that was suspected in our EUS study might also be due to direct damage. Gentle injection into the residual submucosa without deeper insertion of the needle is essential in $\mathrm{LSI}$ procedures.

The limitations of this study include its retrospective design and the limited number of patients. The indication for LSI, type of steroid, and administered dose varied considerably depending on the periods or institutions because no standard method of LSI has been established. The association of LSI with a fragile esophageal wall warrants further investigation. There are also 
some speculations as to the relationship between wall vulnerability and the findings on narrow-band imaging or EUS. Nevertheless, our data are highly suggestive about the efficacy and complications of LSI because we only enrolled ESD patients with large lesions whose number will probably increase in the near future, from multiple institutions.

\section{Conclusion}

LSI therapy is useful for preventing post-ESD stricture, although it might increase the risk of perforation during EBD. EBD should be performed with great caution, especially after LSI, for example, in a stepwise approach starting with a small balloon diameter.

\section{Competing interests}

None

\section{References}

[1] Tsujii Y, Nishida T, Nishiyama O et al. Clinical outcomes of endoscopic submucosal dissection for superficial esophageal neoplasms: a multicenter retrospective cohort study. Endoscopy 2015; 47: 775 - 783

[2] Ono S, Fujishiro M, Niimi K et al. Long-term outcomes of endoscopic submucosal dissection for superficial esophageal squamous cell neoplasms. Gastrointest Endosc 2009; 70: $860-866$

[3] Tamiya Y, Nakahara K, Kominato K et al. Pneumomediastinum is a frequent but minor complication during esophageal endoscopic submucosal dissection. Endoscopy 2010; 42: 8-14

[4] Isomoto H, Yamaguchi N, Minami H et al. Management of complications associated with endoscopic submucosal dissection/endoscopic mucosal resection for esophageal cancer. Dig Endosc 2013; 25: (Suppl. 01): 29-38

[5] Katada C, Muto M, Manabe T et al. Esophageal stenosis after endoscopic mucosal resection of superficial esophageal lesions. Gastrointest Endosc 2003; 57: 165 - 169

[6] Ono S, Fujishiro M, Niimi K et al. Predictors of postoperative stricture after esophageal endoscopic submucosal dissection for superficial squamous cell neoplasms. Endoscopy 2009; 41: 661-665
[7] Ezoe Y, Muto M, Horimatsu T et al. Efficacy of preventive endoscopic balloon dilation for esophageal stricture after endoscopic resection. J Clin Gastroenterol 2011; 45: 222-227

[8] Hanaoka N, Ishihara R, Takeuchi Y et al. Intralesional steroid injection to prevent stricture after endoscopic submucosal dissection for esophageal cancer: a controlled prospective study. Endoscopy 2012; 44: $1007-1011$

[9] Hashimoto S, Kobayashi M, Takeuchi M et al. The efficacy of endoscopic triamcinolone injection for the prevention of esophageal stricture after endoscopic submucosal dissection. Gastrointest Endosc 2011; 74: 1389-1393

[10] Kataoka K, Aoyama I, Mizusawa J et al. A randomized controlled Phase II/III study comparing endoscopic balloon dilation combined with steroid injection versus radial incision and cutting combined with steroid injection for refractory anastomotic stricture after esophagectomy: Japan Clinical Oncology Group Study JCOG1207. Jpn J Clin Oncol 2015; 45: 385-389

[11] Yamashina T, Uedo N, Fujii M et al. Delayed perforation after intralesional triamcinolone injection for esophageal stricture following endoscopic submucosal dissection. Endoscopy 2013; 45: (Suppl. 02): E92

[12] Nagami Y, Shiba M, Tominaga $K$ et al. Locoregional steroid injection prevents stricture formation after endoscopic submucosal dissection for esophageal cancer: a propensity score matching analysis. Surg Endosc 2016; 30: 1441 - 1449

[13] Fujishiro M, Kodashima S, Goto O et al. Endoscopic submucosal dissection for esophageal squamous cell neoplasms. Dig Endosc 2009; 21: $109-115$

[14] Tsujii Y, Kato M, Shinzaki S et al. Polyglycolic acid sheets for repair of refractory esophageal fistula. Endoscopy 2015; 47: (Suppl. 01): E3940

[15] Takahashi H, Arimura Y, Okahara S et al. Risk of perforation during dilation for esophageal strictures after endoscopic resection in patients with early squamous cell carcinoma. Endoscopy 2011; 43: $184-189$

[16] Kishida Y, Kakushima N, Kawata N et al. Complications of endoscopic dilation for esophageal stenosis after endoscopic submucosal dissection of superficial esophageal cancer. Surg Endosc 2015; 29: 2953 2959

[17] Honda M, Nakamura T, Hori Y et al. Feasibility study of corticosteroid treatment for esophageal ulcer after EMR in a canine model. J Gastroenterol 2011; 46: 866-872

[18] Nonaka K, Miyazawa M, Ban S et al. Different healing process of esophageal large mucosal defects by endoscopic mucosal dissection between with and without steroid injection in an animal model. BMC Gastroenterol 2013; 13: 72 